
Not for reproduction, distribution or commercial use.

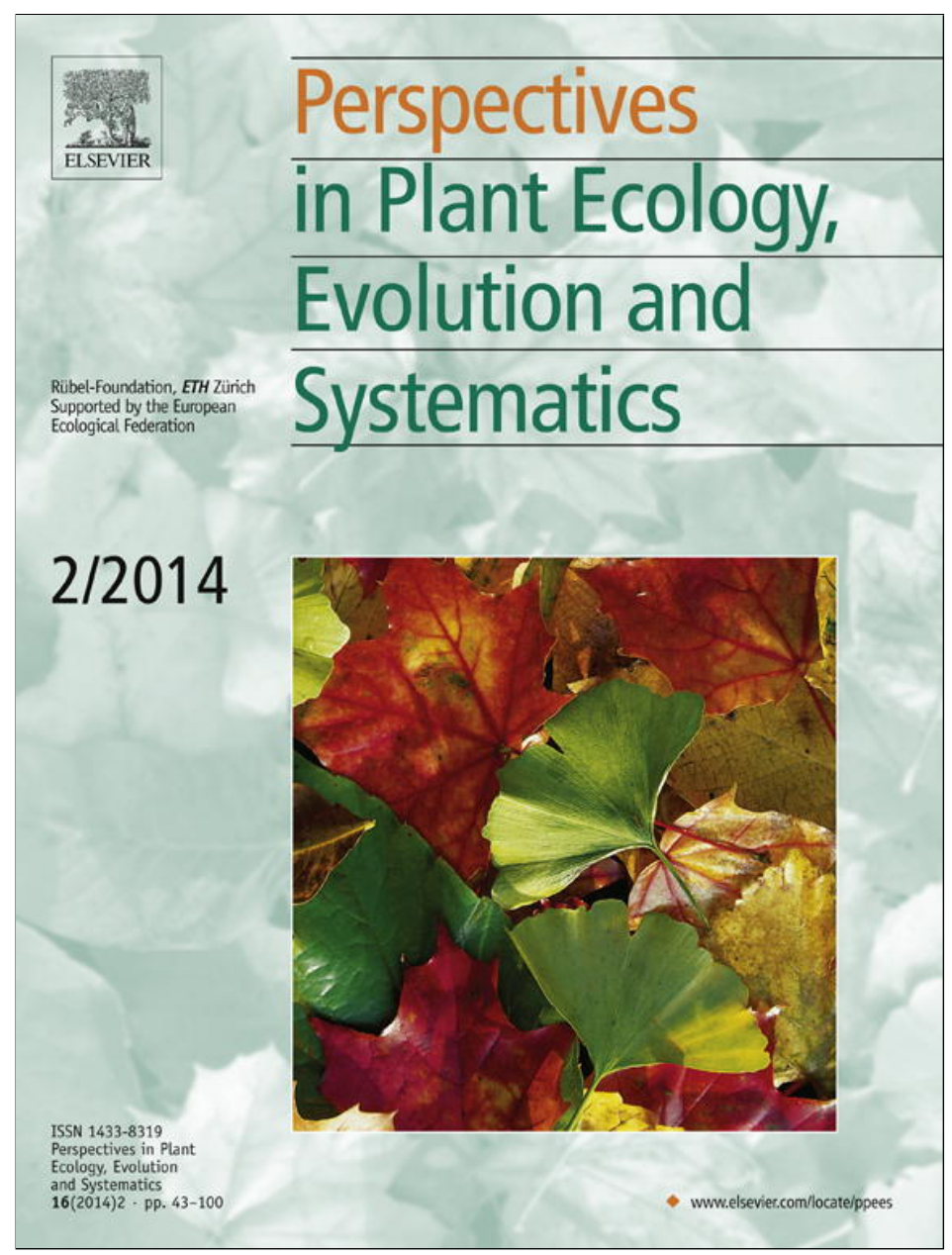

This article appeared in a journal published by Elsevier. The attached copy is furnished to the author for internal non-commercial research and education use, including for instruction at the authors institution and sharing with colleagues.

Other uses, including reproduction and distribution, or selling or licensing copies, or posting to personal, institutional or third party websites are prohibited.

In most cases authors are permitted to post their version of the article (e.g. in Word or Tex form) to their personal website or institutional repository. Authors requiring further information regarding Elsevier's archiving and manuscript policies are encouraged to visit:

http://www.elsevier.com/authorsrights 
Research article

\title{
Negative density dependence and environmental heterogeneity effects on tree ferns across succession in a tropical montane forest
}

\author{
Julia Chacón-Labella ${ }^{a, *}$, Marcelino De la Cruz ${ }^{a}$, Rafael Vicuña ${ }^{b}$, \\ Karla Tapia ${ }^{\mathrm{b}}$, Adrián Escudero ${ }^{\mathrm{a}}$ \\ a Área de Biodiversidad y Conservación, Universidad Rey Juan Carlos, E-28933 Móstoles, Spain \\ b Instituto de Ecología, Universidad Técnica Particular de Loja, CP: 11-01-608 Loja, Ecuador
}

\section{A R T I C L E I N F O}

\section{Article history:}

Received 8 January 2013

Received in revised form 11 February 2014

Accepted 14 February 2014

Available online 23 February 2014

\section{Keywords:}

Negative density dependence

Large-scale heterogeneity

Case-control

Point pattern analysis

Tree ferns

\begin{abstract}
A B S T R A C T
Although tree ferns are an important component of temperate and tropical forests, very little is known about their ecology. Their peculiar biology (e.g., dispersal by spores and two-phase life cycle) makes it difficult to extrapolate current knowledge on the ecology of other tree species to tree ferns. In this paper, we studied the effects of negative density dependence (NDD) and environmental heterogeneity on populations of two abundant tree fern species, Cyathea caracasana and Alsophila engelii, and how these effects change across a successional gradient. Species patterns harbor information on processes such as competition that can be easily revealed using point pattern analysis techniques. However, its detection may be difficult due to the confounded effects of habitat heterogeneity. Here, we mapped three forest plots along a successional gradient in the montane forests of Southern Ecuador. We employed homogeneous and inhomogeneous $K$ and pair correlation functions to quantify the change in the spatial pattern of different size classes and a case-control design to study associations between juvenile and adult tree ferns. Using spatial estimates of the biomass of four functional tree types (short- and long-lived pioneer, shadeand partial shade-tolerant) as covariates, we fitted heterogeneous Poisson models to the point pattern of juvenile and adult tree ferns and explored the existence of habitat dependencies on these patterns. Our study revealed NDD effects for $C$. caracasana and strong environmental filtering underlying the pattern of $A$. engelii. We found that adult and juvenile populations of both species responded differently to habitat heterogeneity and in most cases this heterogeneity was associated with the spatial distribution of biomass of the four functional tree types. These findings show the effectiveness of factoring out environmental heterogeneity to avoid confounding factors when studying NDD and demonstrate the usefulness of covariate maps derived from mapped communities.
\end{abstract}

(c) 2014 Geobotanisches Institut ETH, Stiftung Ruebel. Published by Elsevier GmbH. All rights reserved.

\section{Introduction}

Determining the processes that promote species coexistence and the maintenance of high diversity is a central issue in ecology, especially in mega diverse tropical forests (Wright, 2002). Previous studies have proposed several processes including gap dynamics, niche segregation, ecological drift and negative density dependent relationships (Wright, 2002; Zimmerman et al., 2008).

Negative density dependence (NDD) reduces the aggregation of conspecifics affecting especially early life stages such as saplings or seedlings when they occur in high densities or near conspecific

\footnotetext{
* Corresponding author. Tel.: +34 685489313.

E-mail addresses: juliachacon@gmail.com, julia.chacon@urjc.es (J. Chacón-Labella).
}

adults. Resource competition among congeners and the abundance of specialist pathogens and herbivores increase with density resulting in depressed recruitment in the close vicinity of adults (for a recent review see Terborgh, 2012). It is hypothesized that NDD enhances plant diversity by making space available for other plant species (Janzen, 1970; Connell, 1971). However, NDD effects may be difficult to detect due to the confounding effects of habitat heterogeneity (e.g., habitat filtering), which can affect both adult and juvenile density irrespective of plant-plant interactions.

Tree ferns represent a conspicuous fraction of tropical, temperate and cool wet forests (Smale et al., 1997; Bellingham et al., 1999). Surprisingly, few studies have focused on this biological component (Kramer, 1993; Márquez et al., 1997; Arens, 2001; Jones et al., 2007; Bystriakova et al., 2011) compared to flowering species. Unfortunately, our knowledge on NDD and habitat filtering in other trees cannot be directly applied to tree ferns, as these organisms 
Table 1

Main questions, statistical approach, and related figures of this study.

\begin{tabular}{|c|c|c|}
\hline Questions & Statistical approach & Related figures \\
\hline $\begin{array}{l}\text { (1) Is the spatial distribution of the two tree ferns (Cyathea } \\
\text { caracasana and Alsophila engelii) affected by large-scale } \\
\text { environmental heterogeneity? }\end{array}$ & $\begin{array}{l}L \text {-function of adults and juveniles of the two tree ferns populations, } \\
\text { using a null-model of "complete spatial randomness" (CSR) }\end{array}$ & Fig. 3 \\
\hline $\begin{array}{l}\text { (2) Which factors are driving the spatial heterogeneity on } \\
\text { juveniles and adults of the two tree ferns populations, and } \\
\text { how this factors change across succession? }\end{array}$ & $\begin{array}{l}\text { (a) Fit log-linear models for tree-fern intensity (density) to several } \\
\text { maps summarizing the distribution of four functional tree types } \\
\text { (guilds) in each forest plot } \\
\text { (b) Inhomogeneous- } L \text { function of adults and juveniles of the two tree } \\
\text { ferns, using the weighted-average log-linear models as estimate of the } \\
\text { intensity function }\end{array}$ & $\begin{array}{l}\text { Fig. } 4 \text { and Fig. S1. } \\
\text { Tables } 2 \text { and } 3\end{array}$ \\
\hline $\begin{array}{l}\text { (3) Is NDD affecting the spatial pattern of these two tree } \\
\text { ferns and how are the effects of NDD changing across } \\
\text { succession? }\end{array}$ & $\begin{array}{l}\text { (a) Differences of } K \text {-functions and pair-correlation functions under a } \\
\text { case-control design using a null model of random labeling. } \\
\text { (b) Differences of } K \text {-functions and pair-correlation functions under a } \\
\text { case-control design using a modified random labeling null model }\end{array}$ & $\begin{array}{l}\text { Figs. } 5 \text { and } 6 \text { and Figs. } \\
\text { S2 and S3 }\end{array}$ \\
\hline
\end{tabular}

present two independent life phases (a tiny and relatively simple gametophyte and a well-developed, conspicuous sporophyte) with different biotic and abiotic filters and ecological determinants of their performance (Watkins et al., 2007). To gain insight on how plant diversity is assembled in these forests, we need to address the challenging question of how and where tree ferns recruit.

In this study, we explored the spatial patterns of two abundant tree ferns, Cyathea caracasana and Alsophila engelii, in three contrasting successional stages in a montane tropical forest in southern Ecuador. Our aim was to determine if negative density dependence exists in the studied populations, as widely reported for tropical trees, and if so, to separate the effects of this process from those of other drivers of coexistence, such as habitat filtering or plant-plant interactions (Law et al., 2009). In order to do this, we used recent techniques of spatial point pattern analysis (Wiegand and Moloney, 2004).

Spatial patterns are known to be responses to some underlying ecological processes (McIntire and Fajardo, 2009), and negative density dependent processes are probably among those with a more evident spatial signal (Kenkel, 1988; Moeur, 1997; Plotkin et al., 2002). When NDD operates, adults appear spaced as a function of the intensity of negative dependence and are less aggregated than juveniles (Janzen, 1970; Stoll and Bergius, 2005). Consequently, the existence of NDD and its effects can be determined by analyzing changes in spatial patterns over time (Sterner et al., 1986; Kenkel, 1988; Moeur, 1997; Getzin et al., 2008; Murrell, 2009) or by comparing the spatial distribution of individuals of different ages when no mortality data are available (Getzin et al., 2008; Zhu et al., 2010; Bagchi et al., 2011). Although spatial point pattern analysis is an efficient tool for revealing NDD effects, spatial patterns may also be the result of first-order effects (i.e., coarse scale habitat heterogeneity) operating simultaneously in the community (Chapin et al., 1989; He and Duncan, 2000; Wright, 2002; Wiegand et al., 2007; Murrell, 2009). For example, heterogeneity can cause higher densities of individuals in favorable sites due to microhabitat differences and plant preferences, or higher mortality and poor growth in less favorable sites (Purves and Law, 2002; Wright, 2002; Getzin et al., 2008; Murrell, 2009). However, a clear separation of these two processes and their effects may not always be feasible (Law et al., 2009). For example, plant aggregation could be due to locally suitable environment, which is the opposite of what we would expect under NDD, leading to an increase in clustering along the ontogeny (Murrell, 2009). Thus, in order to detect NDD effects (if present) or other spatial signals that may be influenced by plant-plant interactions, the effects of spatial heterogeneity must also be considered (Law et al., 2009). The importance of environmental heterogeneity in determining the spatial pattern of trees is being increasingly recognized and some approaches have been proposed (e.g., Wiegand et al., 2007; Getzin et al., 2008). However, few attempts have been made to explicitly test the effects of specific environmental factors (but see Bagchi et al., 2011) or community properties (e.g., spatial distribution of functional diversity, but see Perry et al., 2013) as a source of heterogeneity when studying NND or other spatial signals in plant populations.

With this in mind, we fully mapped three plots representing contrasting succession stages in an evergreen tropical montane forest in southern Ecuador. We conducted parallel analyses in successional stages as plant-plant interactions and ontogenetic necessities shift abruptly along succession in tropical forests (Franklin and Rey, 2007). Some studies suggest different tolerance to light environment among tree ferns (Bittner and Breckle, 1995; Arens and Baracaldo, 2000; Arens, 2001; Jones et al., 2006), and both $C$. caracasana and $A$. engelii are long-lived pioneer species which require a high-light environment for successful establishment and survival (Arens, 2001). Therefore, we used the spatial distribution of functional groups of trees with different affinity for light as a rough proxy of light conditions in this forest to account for environmental heterogeneity while examining the existence of NND effects in the populations of these two species.

We specifically aimed to determine: (i) the effect of environmental heterogeneity on the spatial distribution of two age-classes (adults and juveniles) of these two tree ferns, (ii) the role of NDD as a driver of their spatial pattern and (iii) whether the effects of NDD and environmental heterogeneity change across succession.

The specific questions, analyses and related figures of this study are summarized in Table 1.

\section{Materials and methods}

\section{Site description and data collection}

Three plots of approximately 0.5 ha were established and fully mapped in the upper San Francisco River in Prov. ZamoraChinchipe, southern Ecuador (Fig. 1). Plots were located at a distance of less than $1 \mathrm{~km}$ from one another at altitudes around 2000 m.a.s.l., on the steep slopes $\left(30^{\circ}\right)$ of an impressive gorge. Climate is classified as tropical and per-humid (Lehnert, 2007). Mean annual precipitation is around $4000 \mathrm{~mm} /$ year (Rollenbeck, 2006). Two plots were located in the Chamusquín Biological Station of the Universidad Técnica Particular de Loja (UTPL) and the third in the Biological Reserve San Francisco (RBSF). Each plot represents different stages in the succession of the tropical montane rain forest (Beck et al., 2007). The plot in San Francisco $\left(5200 \mathrm{~m}^{2}\right.$ ) is located within an extensive patch of undisturbed tropical montane rainforest (Beck et al., 2007), whereas the two plots in Chamusquín follow the shape of two forest fragments of recently disturbed montane 


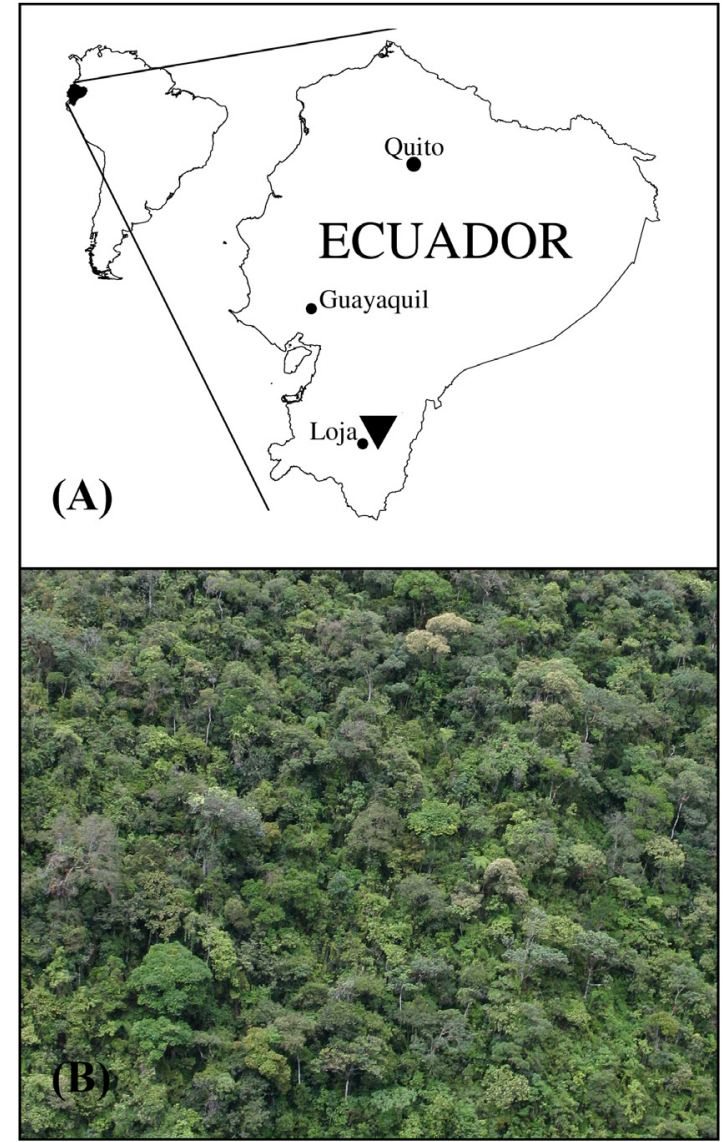

Fig. 1. The location of the three plots in Ecuador and photograph of the San Francisco plot.

forest. Plot Chamusquín A $\left(5610 \mathrm{~m}^{2}\right)$ was severely affected by a forest fire 25 years ago, whereas Chamusquín $B\left(4366 \mathrm{~m}^{2}\right)$ was disturbed by maintenance works on the Loja-Zamora road around 10 years before the mapping took place. We identified the species in the three plots and tagged all individual trees with a $\mathrm{dbh}>5 \mathrm{~cm}$. We measured the height of tree ferns and dbh for the rest of the trees.

We also obtained the position coordinates $(x, y)$ of each individual to the nearest $\mathrm{cm}$ using a measuring tape. All tree species were assigned to one of the four functional types usually considered in tropical forest ecology: short-lived pioneer (SLP), long-lived pioneer (LLP), shade-tolerant (ST) and partial shade-tolerant (PST) (Turner, 2004; Poorter et al., 2006).

We classified each individual tree fern as adult or juvenile on the basis of height, as age is poorly related to $\mathrm{dbh}$ in tree ferns since tree ferns do not undergo secondary growth (Roberts et al., 2005; Mehltreter and García-Franco, 2008). Furthermore, trunk height is frequently used as a proxy for age in tree ferns (Seiler, 1981, 1995; Bittner and Breckle, 1995). Individual tree ferns were classified according to the 99th percentile ( $h 99$ ) of the distribution of individual heights (Bagchi et al., 2011). Tree ferns with a height $>h 99 \times 2 / 3$ were classified as adults, while trees with a height $<h 99 \times 1 / 3$ were classified as juveniles (Fig. 2). Trees with a height between $1 / 3$ and $2 / 3$ of the 99th percentile were excluded from the cohort analyses. Although these classes would probably not agree with a strict demographic classification of adults and juveniles, we used these terms following recent studies on NND in tropical forest (Bagchi et al., 2011) and for the sake of brevity.
Spatial analysis

We analyzed the spatial pattern of tree-ferns using univariate and bivariate versions of Ripley's K-function (Ripley, 1976; Illian et al., 2008) and the pair-correlation function (Stoyan and Stoyan, 1994; Wiegand and Moloney, 2004; Illian et al., 2008). For a homogeneous point pattern where $\lambda$ is pattern intensity (i.e., density), $\lambda K(r)$ is the expected number of points within a circle of radius $r$ around an arbitrary point. Similarly, $\lambda_{j} K_{i j}(r)$ is defined as the expected number of type " $j$ " points within distance $r$ of an arbitrary type " $i$ " point, where $\lambda_{j}$ is the intensity of type " $j$ " points. The paircorrelation function $g(r)$ is related to the derivative of the $K$ function, i.e., $g(r)=K^{\prime}(r) /(2 \pi r)$ and can defined as the expected number of points at a distance approximately equal to $r$ from an arbitrary point, divided by the intensity of the pattern (Illian et al., 2008).

We also used the inhomogeneous $K$-function $[\operatorname{Kinhom}(r)]$ to account for spatial heterogeneity. To compute the inhomogeneous $K$-function it is assumed that the observed point pattern is generated by a two-step process, where an originally homogeneous pattern is thinned according to an inhomogeneous thinning surface $\lambda(x)$, which only depends on the location $x$. This thinning surface describes the environmental heterogeneity and is proportional to the intensity of the two-step process (Baddeley et al., 2000). For a point located at $x$, we expect on average $1 / \lambda(x)$ points for the initial, pre-thinned homogeneous pattern. Having estimated $\lambda(x)$, e.g., from environmental covariates, the inhomogeneous $K$ is therefore calculated as the homogeneous $K$ but weighting each data point by $1 / \lambda(x)$ (Getzin et al., 2008). To facilitate visual interpretation, we used the $L$-function, i.e., square root transformed $K$ : $L(r)=[K(r) / \pi]^{1 / 2}-r$ (Besag, 1977). If the pattern is homogeneous Poisson (i.e., CSR) or inhomogeneous Poisson with intensity function $\lambda(u)$, then $K(r)=\operatorname{Kinhom}(r)=\pi r^{2}$ and $L(r)=\operatorname{Linhom}(r)=0$. Both homogeneous and inhomogeneous $K$-functions were estimated using Ripley's isotropic edge correction (Ripley, 1978). All the functions were estimated up to $25 \mathrm{~m}$ (i.e., $r_{\max }=25 \mathrm{~m}$ ) with steps of $1 \mathrm{~m}$.

\section{Test of heterogeneity}

To assess the existence of heterogeneity, we conducted a CSR test on the adult and juvenile tree fern populations in each plot. Large-scale heterogeneity produces locally high tree densities, which leads to significant increases in the $L$-function at larger scales (Wiegand and Moloney, 2004). Significant positive deviations from a homogeneous Poisson process at $r$ scales larger than the average species interaction distance are accepted as a confirmation of environmental heterogeneity (Wiegand and Moloney, 2004; Getzin et al., 2008). Several studies have pointed out that species interactions in humid tropical forests decrease significantly or are negligible at distances greater than $10 \mathrm{~m}$ (Wiegand et al., 2007; Hubbell et al., 2001; Uriarte et al., 2004). This distance may even be smaller for tree ferns, which have smaller crowns than most trees. Thus, for each tree fern population in each plot, we compared the $L$-function to the 25th lowest and highest value of 999 simulations of the homogeneous Poisson process, and looked for positive deviations for $r$ scales $>10 \mathrm{~m}$. As the simulation envelopes represent point-wise tests and this approach may inflate Type-I error, we performed a goodness-of-fit (GOF) test in the range 10-25 $\mathrm{m}$ using the $u$ statistic (Diggle, 2003; Loosmore and Ford, 2006).

\section{Estimation of intensity functions}

For forest stand patterns which suggested large-scale heterogeneity, we fitted an inhomogeneous Poisson model to each tree fern population using the ppm() function of spatstat (Baddeley 
A

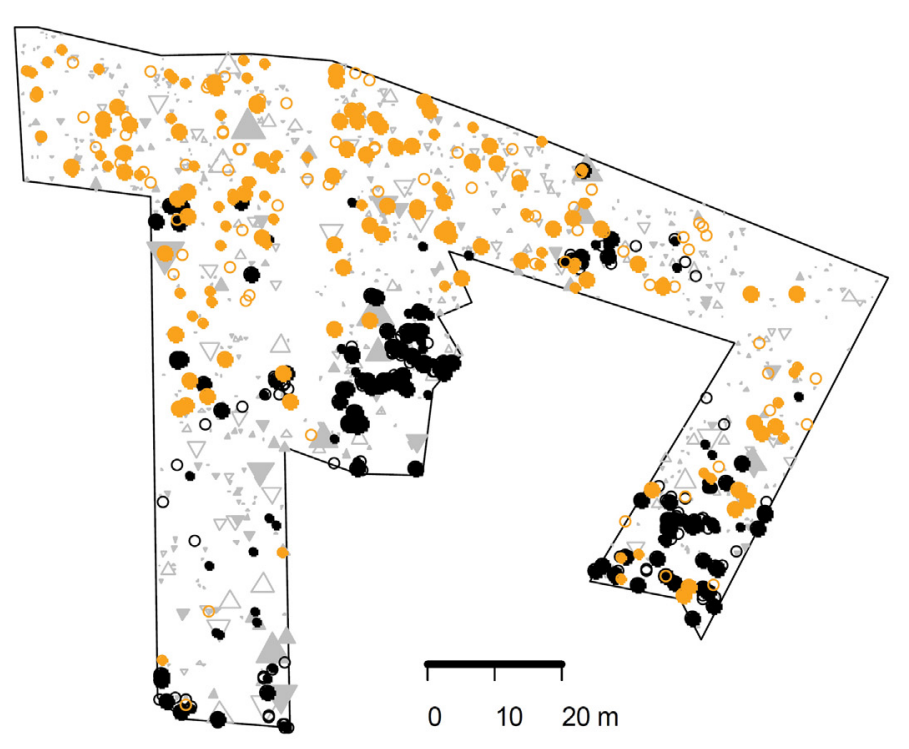

B

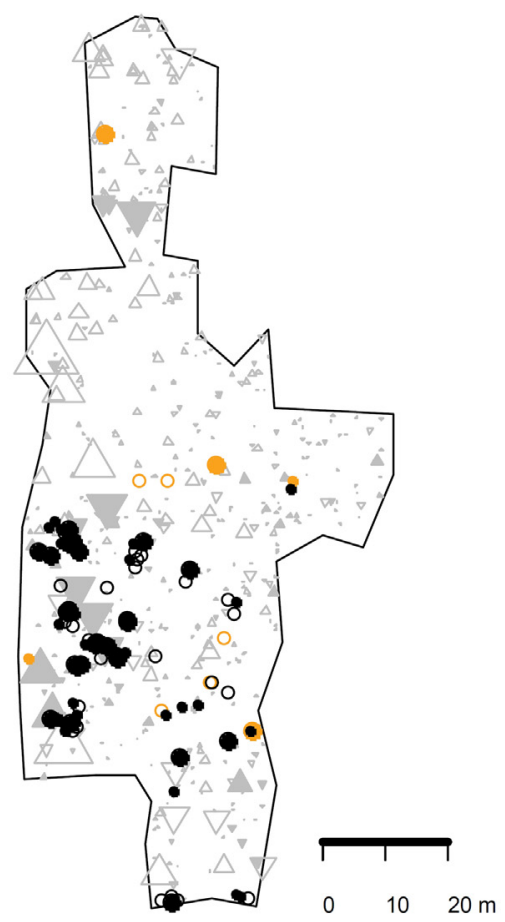

C

\author{
- Alsophyla 'adults' \\ - Alsophyla 'medium sized' \\ - Alsophyla 'juveniles' \\ - Cyathea 'adults' \\ - Cyathea 'medium sized' \\ - Cyathea 'juveniles' \\ $\nabla$ Long-lived pioneers \\ Short-lived pioneers \\ $\checkmark$ Shade tolerants \\ $\triangle$ Partial shade tolerants
}

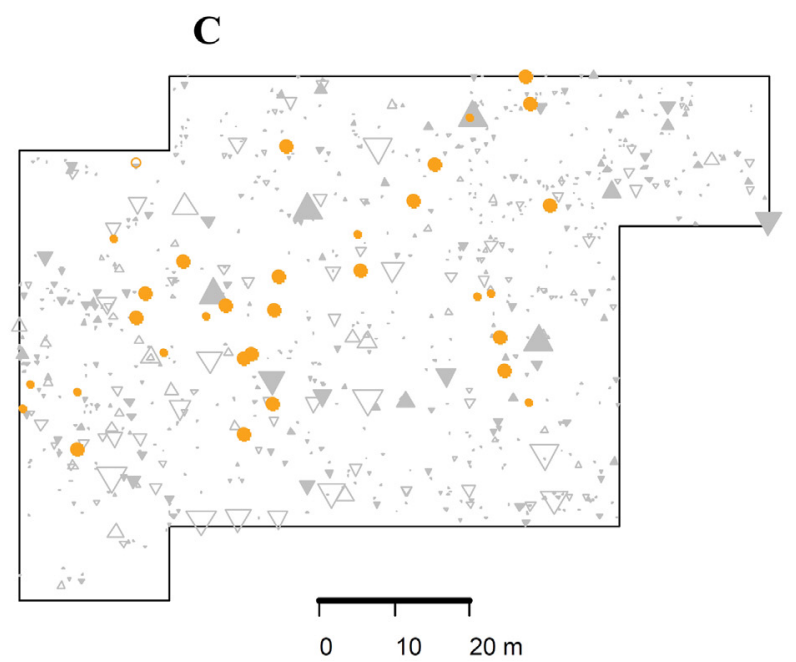

Fig. 2. Maps of the studied tree fern populations. (A) Chamusquín A. (B) Chamusquín B. (C) San Francisco. Both Chamusquín A and B plots follow the shape of two small forest fragments. San Francisco is a polygonal plot set in a large forest patch. Black dots: Alsophila engelii. Orange dots: Cyathea caracasana. Gray symbols represent individuals of other species, classified in the four functional types considered in the study. Size of the gray symbols is proportional to the basal area of each individual.

and Turner, 2005). This function fits the intensity of the observed point pattern as a log-linear function of one or several covariates maximizing likelihood (Baddeley and Turner, 2000). This is done using GLM likelihood-based tools for model selection and evaluation (Baddeley and Turner, 2005). When modeling point pattern intensity, covariates can take the form of a map showing the variation of the environmental factor of interest throughout the area (the window) of the pattern. Our working hypothesis was that light demands in the competing neighborhood have a clear effect on the growth and survival of these tree ferns, determining the position they can attain in the canopy to survive and reproduce. For this study, we built several covariate maps summarizing the distribution of four functional tree types in each plot: short-lived pioneer (SLP), long-lived pioneer (LLP), shade-tolerant (ST) and partial shade-tolerant (PST). These can be considered indicators of important environmental conditions, such as light availability and intensity of local interspecific competition (Turner, 2004; Poorter et al., 2006). For instance, a high abundance of short-lived pioneers at a point would indicate high light availability at recruitment and local inter-specific competition. We built biomass distribution maps for each functional type in each plot, smoothing basal-area values of individual trees on a grid of $1 \mathrm{~m}^{2}$ resolution with an isotropic Gaussian kernel (with sigma values of 5, 10, 15 and $20 \mathrm{~m}$ ). The sigma value in these functions is the standard deviation of the Gaussian kernel. Changing sigma values allows us to explore the scale at which each covariate best explains the spatial pattern of the two tree ferns. As both $C$. caracasana and A. engelii are longlived pioneers (LLP), the computation of the LLP covariate for their models excluded the basal area of $C$. caracasana and $A$. engelii tree ferns. We also computed smoothed density estimates of adults ( $C$. caracasana or A. engelii) with Gaussian kernels of variable sigma ( 5 , 10,15 and $20 \mathrm{~m}$ ) as additional covariates to estimate the intensity 
functions of juveniles. We fitted log-linear models of tree intensity as a function of each individual spatial covariate for each juvenile and adult population. Among the four maps for each functional type (one for each sigma), we selected the map whose model had the smallest AIC for each population. We did the same with the adult-density covariates for the juvenile populations. This provided us with four covariates for each adult population and five covariates for each juvenile population (the four functional types plus the adults). We then computed variance inflation factors to exclude correlated covariates that could affect model fit. Finally, we fitted models with all combinations of the remaining covariates for each population. These models were combinations of 3 ( 7 models), 4 (15 models) or 5 covariates ( 31 models), depending on the existence of collinearity and age class. As there was over-dispersion in responses, we used the overdispersion parameter ( $\mathrm{psi}$ ) of the most complex model for each population to compute the quasi AIC (QAIC) for each model (Burnham and Anderson, 2002).

For each population, models were ranked according to their QAIC. $\triangle$ QAICs were computed relative to the first model (i.e., the model with the smallest QAIC), and all models with $\triangle$ QAIC $>4$ were discarded, as they have less empirical support than models with $\triangle$ QAIC $<4$ (Burnham and Anderson, 2002, p. 170). We used $\Delta$ QAIC values to compute the Akaike weight $\left(w_{i}\right)$ of each of the selected models, and $w_{i}$ was used to compute a weighted-average model (Burnham and Anderson, 2002) for each population. The weightedaverage models provided a parametric estimate of the intensity function of each population. To assess the effect of each covariate on the distribution of each population, we computed a relative importance value (RIV) based on the weight of the models in which they were included. For this, we summed the $w_{i}$ values of all the models in which each covariate appeared (Burnham and Anderson, 2002).

\section{Spatial model evaluation}

To test whether the models accounted for the heterogeneity in the observed point pattern, we performed a "spatial" model evaluation. This consisted of evaluating the consistency of the inhomogeneous- $L$ function of the pattern with the fitted inhomogeneous Poisson process. This is similar to the usual null test of complete spatial randomness, i.e., computing simulation envelopes, but in this case derived from the inhomogeneous Poisson model. Thus, the weighted-average log-linear models were used as estimates of the intensity functions. The simulation procedure when using the inhomogeneous $L$ consists of two steps. First, a homogeneous Poisson process is simulated in the observed window, and then each simulated point $x$ is "thinned" with a probability proportional to $1 / \lambda(x)$, where $\lambda(x)$ is the intensity estimated at location $x$ (Baddeley et al., 2000). If the fitted intensity surfaces correctly account for the heterogeneity, the inhomogeneous $L$ function should not deviate significantly from the simulated envelopes at scales $r>10 \mathrm{~m}$.

\section{Test of negative density dependence (NDD)}

Negative density dependence results in a loss of clustering among individuals of the same species due to mortality caused by species-specific natural enemies (pest, pathogens and herbivores) and competition among congeners. This mechanism can be evaluated by surveying differences of $K$ functions and pair-correlation functions ( $g$-functions) under a case-control design (Diggle and Chetwynd, 1991). This design originated in epidemiological literature but has recently been applied to plant ecology (De la Cruz et al., 2008; Getzin et al., 2008). It uses a "control" pattern to account for the effects of heterogeneity in a population of "cases" (i.e., the population of interest). The null model usually employed is random labeling, i.e., if the pattern of the cases is not different from that of controls, they are a random subset of the joint population of cases and controls (Getzin et al., 2008). Assuming that adult spatial patterns indicate a favorable habitat for each species, we used the pattern of adults as a control and treated juveniles as cases. As $K$ and $g$-functions are invariant under random labeling (Dixon, 2002), we expected that $K_{j}(r)=K_{a}(r)=K_{j a}(r)$, where subscripts $j$ and $a$ indicate juvenile and adult populations, respectively. Under this design and the null-model, $K_{a}(r)-K_{j}(r)$ has an expected value of 0 . Thus, if NDD is occurring, we would expect significant negative values at short scales $r$. Positive deviations at short scales would indicate increased clustering with ontogeny (Murrell, 2009), while deviations at large scales would indicate differences in the response of the two sizes or age classes to large scale heterogeneity.

We also employed the differences $K_{a}(r)-K_{a j}(r)$ and $K_{j}(r)-K_{j a}(r)$, which have an expected value of 0 under random labeling and indicate whether adult and juvenile individuals follow the same overall pattern. If $K_{a}(r)-K_{a j}(r)=0$, juveniles surround adults at the scale $r$ in the same way as adults surround adults. In other words, they exploit the available habitat in the same way at these scales. Positive deviations at short scales would indicate a segregation of adults, implying some kind of inhibition on regeneration and recruitment (e.g., Janzen-Connell effects, etc.). Negative deviations at short scales would indicate increased regeneration in the proximity of adults, and thus, the existence of some facilitative effects of adults on juveniles. Deviations at large scales would usually mean a difference in the realized habitat, i.e., different responses of adults and juveniles to environmental heterogeneity, indicating that some strong environmental filter may be controlling access to the adult class. The difference $K_{j}(r)-K_{j a}(r)$ reveals if there is an additional pattern within juveniles (cases) that is independent of adults (controls). Positive deviations at short scales, for instance, would mean that juveniles regenerated in large gaps favorable for establishment and survival (Getzin et al., 2008), while negative deviations would indicate an over-mixing of juveniles among adults, i.e., they recruit interspersed in adult clusters. We complemented the analysis with differences of pair correlation functions which allow the isolation of deviation from the null model at specific distance ranges due to their non-cumulative properties (Wiegand and Moloney, 2004).

The traditional case-control design (and random labeling null model) assumes that the intensity functions of both adult and juvenile populations are the same, i.e., they are determined by the intensity of the population "at risk", which is usually not estimated (Diggle and Chetwynd, 1991). To test the effects of the fitted environmental heterogeneity on NND, we employed a modified random labeling null model ("spatially varying random labeling") in which the probability of being a juvenile (i.e., a case) was proportional to spatially varying probabilities $p=\lambda_{j}(x) /\left[\lambda_{j}(x)+\lambda_{a}(x)\right]$, where $\lambda_{a}(x)$ and $\lambda_{j}(x)$ are the intensity surfaces fitted for adult and juveniles, respectively. For each relabeling, we randomly selected the same number of juveniles of the original population without replacement from the entire set of adults and juveniles, with each individual's probability of selection proportional to $p$ (Diggle et al., 2007; Bagchi et al., 2011). With this null model, the expected differences of $K$ and $g$-functions are not necessarily 0 , but positive and negative deviations from the averaged simulated differences are interpreted in the same way as for the plain random labeling null model.

The significance of the observed difference-functions was assessed by computing $95 \%$ simulation envelopes from 999 subsets of $n_{j}$ juveniles randomly resampled from the joined pattern of $n_{j}$ juveniles plus $n_{a}$ adults, and computing GOF tests. Statistical and spatial analyses were carried out using R 2.15 software (R 

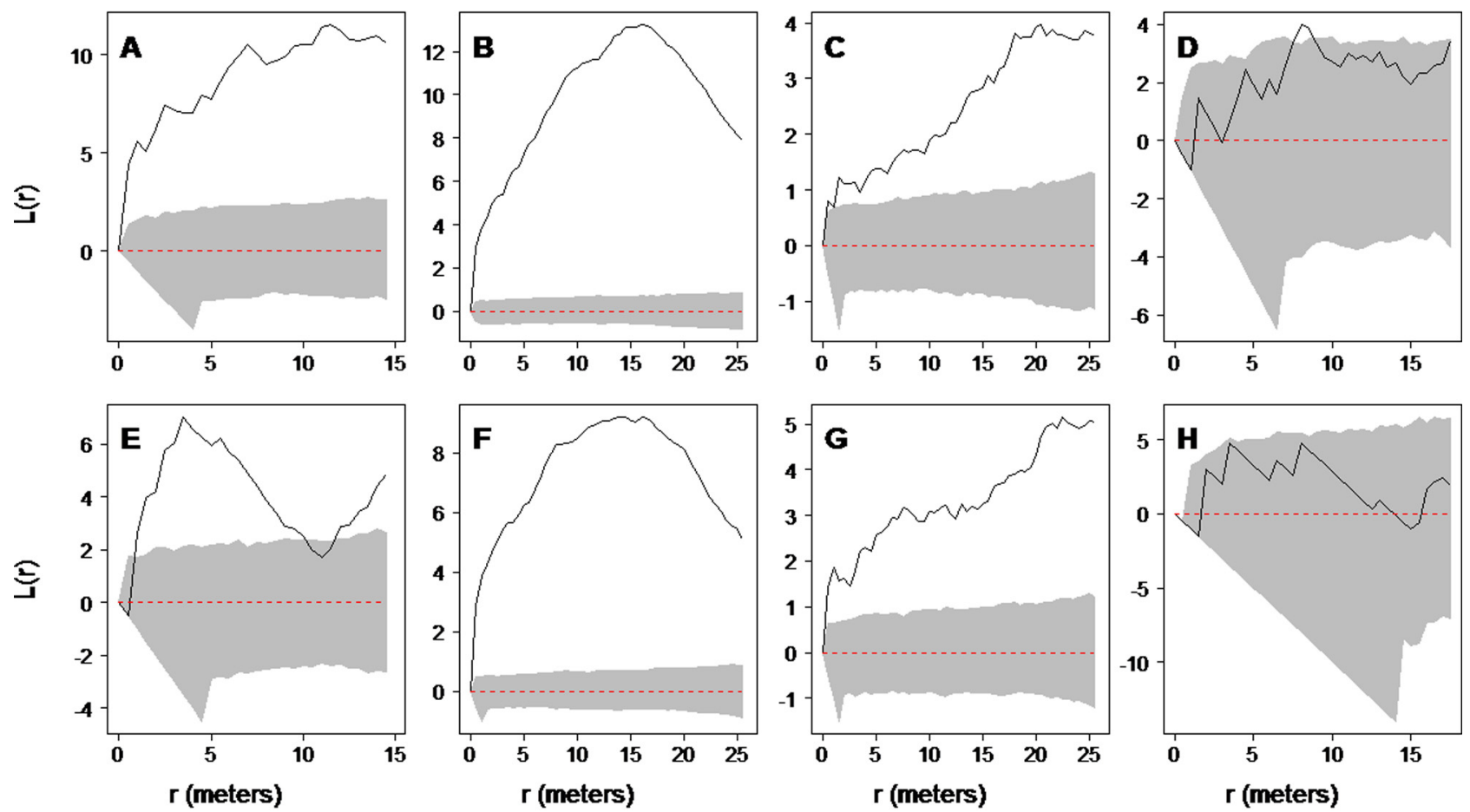

Fig. 3. Patterns of adult and juvenile tree ferns of Cyathea caracasana and Alsophila engelii, compared to a null model of complete spatial randomness (CSR) using the homogeneous L-function. (A and B) Alsophila engelii adults in Chamusquín B and Chamusquín A plots, respectively. (C and D) Cyathea caracasana adults in Chamusquín-A and San Francisco plots. (E and F) Alsophila engelii juveniles in Chamusquín-B and Chamusquín-A plots, respectively. (G and H) Cyathea caracasana juveniles in Chamusquín-A and San Francisco plots.

Development Core Team, 2011). Most of the spatial analyses were conducted with the R package spatstat (Baddeley and Turner, 2005), while differences of $K$ and $g$-functions were conducted with the R package ecespa (De la Cruz et al., 2008). The R code to select and average ppm models on the basis of QAIC is provided as supplementary documentation.

\section{Results}

We mapped a total of 2910 individuals $(\mathrm{dbh}>5 \mathrm{~cm}$ ) of 257 species in the three study plots. C. caracasana and A. engelii accounted for 472 and 715 individuals, respectively. The total number of species per plot, individuals per functional type, basal area per functional type and individuals per height class is summarized in Table S1. Note that no A. engelii individuals were found in the San Francisco plot and almost no $C$. caracasana individuals were classified as adults or juveniles in Chamusquín B plot (Table S1).

\section{Test of heterogeneity}

The patterns of $C$. caracasana juveniles (Fig. $3 \mathrm{H}$ ) and adults in the San Francisco plot (Fig. 3D) were clearly consistent with a homogeneous Poisson process, although these patterns could also be caused by the low number of individuals in the plot. All the other studied patterns of both $C$. caracasana and $A$. engelii juveniles and adults were clearly heterogeneous (the GOF test between $r=10$ and $25 \mathrm{~m}$ had $p$-value $<0.01$ in all cases; Fig. $3 \mathrm{~A}-\mathrm{G}$ ).

\section{Does community structure (guilds) explain the heterogeneous distribution of tree ferns?}

Except for $A$. engelii adults in Chamusquín A, all the fitted models accounted for the heterogeneity detected in the previous analyses (Fig. 4). According to the fitted models, A. engelii adults in Chamusquín B were positively affected by the basal area of shade-tolerant (ST) and partial shade-tolerant (PST) functional types (Table 2). In Chamusquín A, the averaged model included positive effects of the biomass of short-lived pioneers (SLP) on the intensity of $A$. engelii adults, although model evaluation showed that this model did not account for the observed heterogeneity. In Chamusquín A, $C$. caracasana adults were positively affected by long-lived pioneers (LLP). In San Francisco, the averaged model for C. caracasana adults showed no significant effects of any of the considered covariates. The spatial evaluation showed that both the heterogeneous and homogeneous Poisson models produced similar results.

Except for $C$. caracasana in San Francisco, all models for juvenile tree ferns included significant positive effects of the abundance of conspecific adults (Table 3 ). In Chamusquín $\mathrm{B}$, the models for $A$. engelii juveniles also found positive effects of SLP. The averaged model in this plot included a significant effect of LLP. C. caracasana juveniles in Chamusquín A were negatively affected by SLP. As found for adults in San Francisco, the averaged model for $C$. caracasana juveniles did not reveal significant effects of any of the considered covariates. All significant effects corresponded to covariates with RIV $=1$ (i.e., they were selected in all models with $\triangle \mathrm{QAIC}<4$ ). For adults, the scale selected for most of the significant covariates was $20 \mathrm{~m}$ (the largest of the four). In the case of juveniles, the scale selected for the influence of conspecific adults was 20 or $15 \mathrm{~m}$, while the scale for functional type covariates was 5 or $10 \mathrm{~m}$. In summary, habitat models for juvenile and adults of the same species did not include any common significant covariates (Tables 2 and 3).

After fitting the heterogeneous Poisson models (see intensity surfaces in Supplementary material, Fig. S1), the spatial evaluation revealed additional short-scale clustering of $A$. engelii juveniles in both Chamusquín B (from 0 to $3 \mathrm{~m}$, GOF test $p$-value $=0.029$ ) and Chamusquín A (from 0 to $15 \mathrm{~m}, p$-value $=0.005$ ) (Fig. $4 \mathrm{E}$ and $\mathrm{F}$ ). 

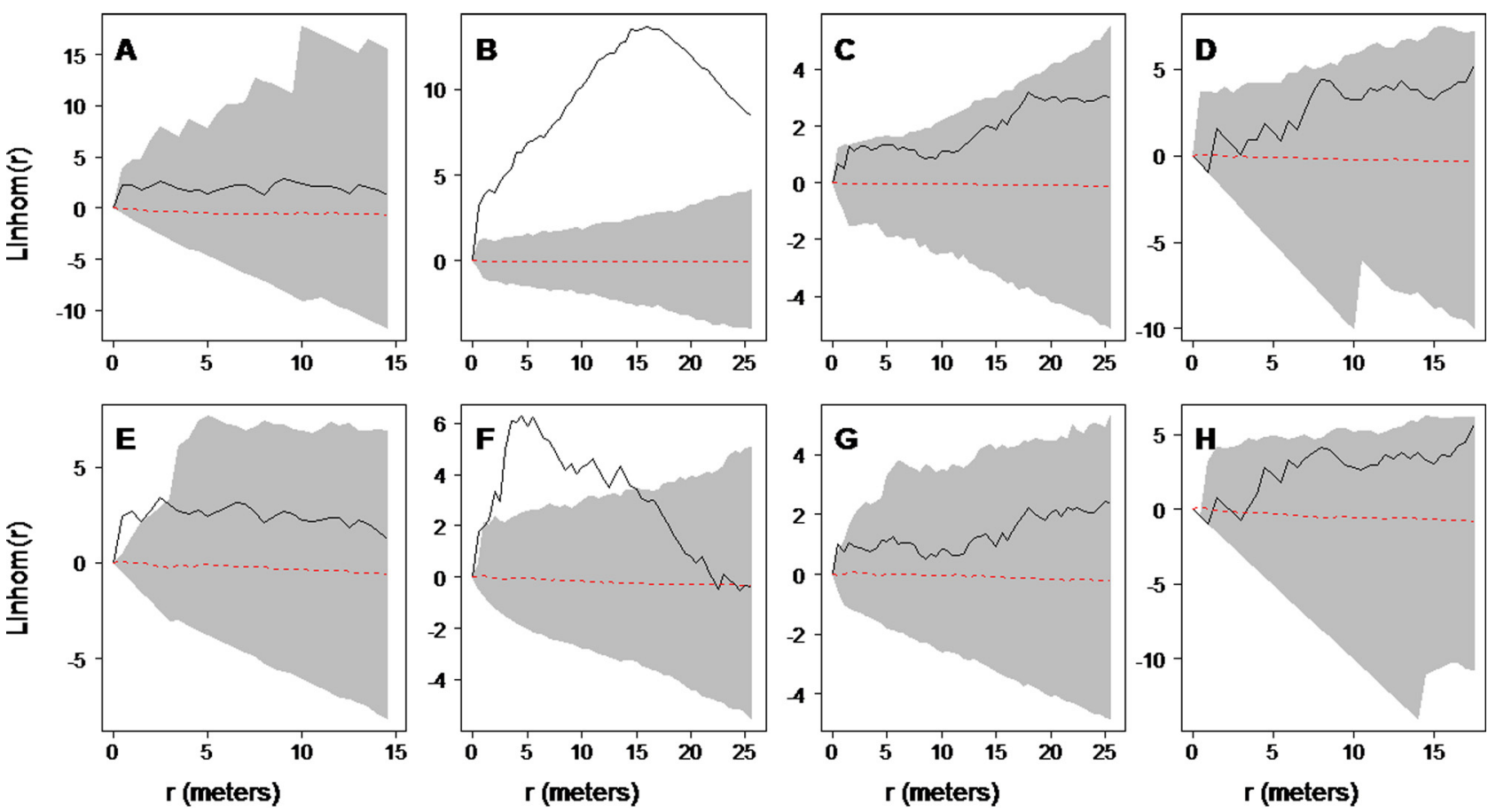

Fig. 4. Patterns of adult and juvenile tree ferns of Cyathea caracasana and Alsophila engelii compared to the fitted heterogeneous Poisson models using the inhomogeneous L-function. (A and B) Alsophila engelii adults in Chamusquín B and Chamusquín A plots, respectively. (C and D) Cyathea caracasana adults in Chamusquín A and San Francisco plots. (E and F) Alsophila engelii juveniles in Chamusquín B and Chamusquín A plots, respectively. (G and H) Cyathea caracasana juveniles in Chamusquín A and San Francisco plots.

The inhomogeneous- $L$ function of $A$. engelii adults in Chamusquín $A$ (Fig. 4B) significantly exceeded the simulation envelopes at scales ranging from 0 to $25 \mathrm{~m}$ (GOF test $p$-value $=0.001$ ), indicating that the fitted model does not explain the heterogeneity in the spatial pattern.

\section{Does negative density dependence occur in tree fern populations?}

In general, both $K$ and $g$-function differences produced similar results. In Chamusquín $\mathrm{A}$, the difference $g_{a}-g_{j}$ with the null model of random labeling showed that $C$. caracasana juveniles were significantly more aggregated than adults up to $r=3 \mathrm{~m}$ (GOF $p$-value $=0.002$; Fig. $5 \mathrm{~A}$ ). The difference $g_{j}-g_{j a}$ departed significantly from the random labeling null model up to $r=6 \mathrm{~m}$ (GOF $p$-value $=0.001 ;$ Fig. $5 \mathrm{C}$ ), indicating strong juvenile segregation, i.e., the clustering of juveniles is independent of the adult pattern. The apparent segregation of adults between 0 and $2 \mathrm{~m}$ (i.e., $g_{a}-g_{a j}>0$ ) was significant (GOF test $p$-value: 0.037; Fig. 5B). Almost identical results were obtained with the null model of spatially varying random labeling (Fig. $6 \mathrm{~A}-\mathrm{C}$ and Fig. S3A-C). For A. engelii in Chamusquín $A$, the null model of random labeling showed that the clustering of adults and juveniles was similar in the $0-7 \mathrm{~m}$ range (GOF $p$-value $=0.165$; Fig. 5D), but adults were significantly more aggregated between 7 and $14 \mathrm{~m}$ (GOF $p$-value $=0.016$; Fig. 5D). The empirical $g_{a}-g_{a j}$ difference also departed significantly from the random labeling null model at scales between 0 and $12 \mathrm{~m}$ (GOF $p$-value $=0.006$; Fig. 5E), indicating segregation of adults in this range. On the other hand, $g_{j}-g_{j a}$ showed significant over-mixing of

Table 2

Parameter estimates for the average of the selected log-linear models of intensity for each population of adult tree ferns. Covariates are smoothed basal areas of long-lived pioneers (LLP), short-lived pioneer (SLP), shade-tolerant (ST) and partial-shade tolerant (PST) trees. Scale: standard deviation (m) of the Gaussian kernel employed to build the spatial covariates. wEstimate, weighted estimate of the coefficients in the averaged model; wSE, weighted standard error of the averaged coefficients; RVI, relative value importance of each covariate in each model; $P, P$-values. Bold font indicate significant results at $P<0.05$. Italics indicate significant results at $P<0.1$.

\begin{tabular}{|c|c|c|c|c|c|c|c|}
\hline Population & Covariate & Scale & wEstimate & wSE & $P$ & RVI & $P$ \\
\hline \multirow[t]{4}{*}{ Alsophila, Chamusquín B } & ST & 20 & 0.014 & 0.005 & 0.003 & 1.00 & 0.417 \\
\hline & PST & 20 & 0.025 & 0.006 & 0.000 & 1.00 & 0.063 \\
\hline & SLP & 10 & -0.003 & 0.005 & 0.494 & 0.45 & 0.583 \\
\hline & LLP & 10 & 0.005 & 0.006 & 0.478 & 0.44 & 0.365 \\
\hline \multirow[t]{4}{*}{ Alsophila, Chamusquín A } & SLP & 10 & 0.010 & 0.002 & 0.000 & 1.00 & 0.011 \\
\hline & LLP & 20 & -0.005 & 0.005 & 0.312 & 0.63 & 0.544 \\
\hline & PST & 10 & -0.001 & 0.002 & 0.428 & 0.55 & 0.222 \\
\hline & ST & 15 & 0.001 & 0.003 & 0.616 & 0.29 & 0.233 \\
\hline \multirow[t]{3}{*}{ Cyathea, Chamusquín A } & LLP & 20 & 0.028 & 0.011 & 0.012 & 1.00 & 0.723 \\
\hline & SLP & 10 & -0.003 & 0.003 & 0.373 & 0.55 & 0.358 \\
\hline & ST & 20 & 0.000 & 0.003 & 0.937 & 0.33 & 0.717 \\
\hline \multirow[t]{3}{*}{ Cyathea, San Francisco } & LLP & 15 & -0.001 & 0.002 & 0.548 & 0.50 & 0.574 \\
\hline & SLP & 5 & -0.001 & 0.002 & 0.572 & 0.47 & 0.604 \\
\hline & PST & 20 & 0.002 & 0.009 & 0.853 & 0.41 & 0.962 \\
\hline
\end{tabular}


Table 3

Parameter estimates for the average of the selected log-linear models of intensity for each population of juvenile tree ferns. Covariates are smoothed densities of adults of the same species (AD) and smoothed basal areas of long-lived pioneers (LLP), short-lived pioneer (SLP), shade-tolerant (ST) and partial-shade tolerant (PST) trees. Scale: standard deviation (meters) of the Gaussian kernel employed to build the spatial covariates. wEstimate, weighted estimate of the coefficients in the averaged model; wSE, weighted standard error of the averaged coefficients; RVI, relative value importance of each covariate in each model; $P, P$-values. Bold font indicate significant results at $P<0.05$. Italics indicate significant results at $P<0.1$.

\begin{tabular}{|c|c|c|c|c|c|c|c|}
\hline Population & Covariate & Scale & wEstimate & wSE & $P$ & RVI & $P$ \\
\hline \multirow[t]{4}{*}{ Alsophila, Chamusquín B } & AD & 20 & 219.518 & 50.469 & 0.000 & 1.00 & 0.001 \\
\hline & $S L P$ & 5 & 0.000 & 0.001 & 0.522 & 0.38 & 0.062 \\
\hline & LLP & 20 & 0.006 & 0.010 & 0.538 & 0.37 & 0.589 \\
\hline & ST & 10 & 0.000 & 0.001 & 0.916 & 0.28 & 0.364 \\
\hline \multirow[t]{4}{*}{ Alsophila, Chamusquín A } & AD & 15 & 51.199 & 4.252 & 0.000 & 1.00 & 0.000 \\
\hline & $L L P$ & 10 & 0.013 & 0.002 & 0.000 & 1.00 & 0.052 \\
\hline & ST & 10 & -0.001 & 0.001 & 0.572 & 0.33 & 0.213 \\
\hline & $S L P$ & 10 & 0.000 & 0.001 & 0.826 & 0.28 & 0.050 \\
\hline \multirow[t]{5}{*}{ Cyathea, Chamusquín A } & AD & 20 & 103.647 & 27.695 & 0.000 & 1.00 & 0.069 \\
\hline & SLP & 10 & -0.009 & 0.003 & 0.011 & 1.00 & 0.173 \\
\hline & PST & 20 & 0.002 & 0.004 & 0.595 & 0.30 & 0.344 \\
\hline & ST & 15 & 0.002 & 0.004 & 0.610 & 0.30 & 0.501 \\
\hline & LLP & 20 & -0.001 & 0.005 & 0.786 & 0.26 & 0.727 \\
\hline \multirow[t]{4}{*}{ Cyathea, San Francisco } & $\mathrm{AD}$ & 10 & 96.138 & 119.766 & 0.422 & 0.52 & 0.341 \\
\hline & SLP & 20 & 0.004 & 0.006 & 0.529 & 0.43 & 0.789 \\
\hline & LLP & 15 & -0.001 & 0.002 & 0.599 & 0.39 & 0.648 \\
\hline & PST & 5 & 0.002 & 0.003 & 0.573 & 0.39 & 0.747 \\
\hline
\end{tabular}

juveniles and adults between 10 and $12 \mathrm{~m}$ (GOF $p$-value $=0.041$; Fig. 5F), while $K_{j}-K_{j a}$ found no significant segregation of juveniles at any spatial scale (supplementary material Fig. S2F). On the contrary, the spatially varying null model showed that adults were significantly more aggregated than juveniles up to $r=18 \mathrm{~m}$ (Fig. 6D, GOF $p$-value $=0.002$ ) and indicated that was no segregation of adults at all scales (Fig. 6E). Considering the heterogeneity, $g_{j}-g_{j a}$ points to the over-mixing of juveniles with adults up to $18 \mathrm{~m}$ (Fig. 6F, GOF $p$-value $=0.001$ ).

In Chamusquín $\mathrm{B}$, the random labeling null model showed that A. engelii adults were more clustered than juveniles in the 3-10 m range $\left(\mathrm{GOF} p\right.$-value $=0.008$; Fig. $5 \mathrm{G}$ ), and the difference $g_{a}-g_{a j}$ was significantly positive from 0 to $6 \mathrm{~m}$ (GOF $p$-value $=0.018$; Fig. $5 \mathrm{H}$ ). The difference $g_{j}-g_{j a}$ was significantly negative from 4 to $10 \mathrm{~m}$ (GOF $p$-value $=0.012$, Fig. 5I). However, when using the spatially varying null model the segregation among adults disappeared (Fig. $6 \mathrm{H}$, GOF $p$-value $=0.152$ ) and the over-mixing of adults was confirmed (Fig. 6I, GOF $p$-value $=0.016$ ).

In the San Francisco plot, $C$. caracasana adults and juveniles were similarly aggregated and showed no segregation at any spatial scale when analyzed with both $K$ - and $g$-functions independent of the null model employed (Figs. 5J-L and 6J-L, and supplementary material Figs. S2J-L and S3J-L). However, these results should be considered with caution because of the low sample size.

\section{Discussion}

Negative density dependence is a basic mechanism regulating species coexistence and the maintenance of species diversity in tropical forests. However, detecting the effects of density dependence may not always be straightforward due to habitat heterogeneity (Wiegand et al., 2007; Getzin et al., 2008). This makes it difficult to determine the ecological processes driving the spatial structure of the different biological components of the system under study (McIntire and Fajardo, 2009). In our case, we considered habitat heterogeneity and its effect on the spatial pattern of two dominant tree ferns in two different ways. We first accounted for the effect of habitat heterogeneity in the detection of density dependence, and secondly, we modeled the spatial pattern of the two tree ferns using some spatial covariates. The first approach allowed us to detect the effects of a density dependent process without the confounding effect of species habitat preferences (i.e., abiotic habitat filtering). The second approach allowed us to propose and test several hypotheses to explain the spatial distribution of tree ferns. This involved detecting specific shapers of the spatial pattern including mainly plant-plant interactions.

Our study only revealed evidence of NDD (i.e., a decrease in the clustering of adults compared to juveniles) for $C$. caracasana in Chamusquín A. The difference functions $K_{a}-K_{a j}$ and $K_{j}-K_{j a}$ detected additional segregation of both juveniles and adults, suggesting that some process(es) compatible with NDD may be interfering with the recruitment of juveniles in the neighborhood of adults. In fact, this kind of spatial signature has sometimes been interpreted as evidence of an inhibitory effect of adults (e.g., Janzen-Connell effects) or the preference of juveniles to recruit in large gaps (Getzin et al., 2008). Our models of the intensity of juveniles and adults showed that they are responding to different processes. Adults are positively associated with the abundance of long-lived pioneers (LLPs), while juveniles are negatively associated with short-lived pioneers (SLP). In fact, $C$. caracasana individuals grow more rapidly and reproduce almost exclusively under conditions of full sun (Arens, 2001). In his study, Arens documented a height growth rate of $4.8 \mathrm{~cm} / \mathrm{yr}(0.4 \mathrm{~cm} / \mathrm{month})$ in the forest understory and $16.8 \mathrm{~cm} / \mathrm{yr}(1.4 \mathrm{~cm} / \mathrm{month})$ in open habitats. A similar growth pattern has been documented for Cyathea delgadii in both closed and open habitats in Costa Rica (Bittner and Breckle, 1995). Consequently, adult individuals of $C$. caracasana in Chamusquín A probably recruited together with other LLP trees immediately after perturbation, whereas juvenile individuals recruited in a different context, i.e., in small gaps that periodically appear in the developing forest once the canopy is closed (Homeier and Breckle, 2008). The negative association between $C$. caracasana juveniles and short-lived pioneer trees (SLP) may be related to strong competition between these two functional types after gap creation. When a gap appears, pioneer species try to colonize the gaps rapidly by growing intensely in height (Whitmore, 1989), while suppressed individuals of LLP species present before gap creation grow in height due to an increase in light. In this context, competition between the two groups (with different life spans) may occur (Homeier and Breckle, 2008). On the contrary, both $C$. caracasana juveniles and adults in the mature forest of San Francisco were similarly aggregated, and their intensities were not 

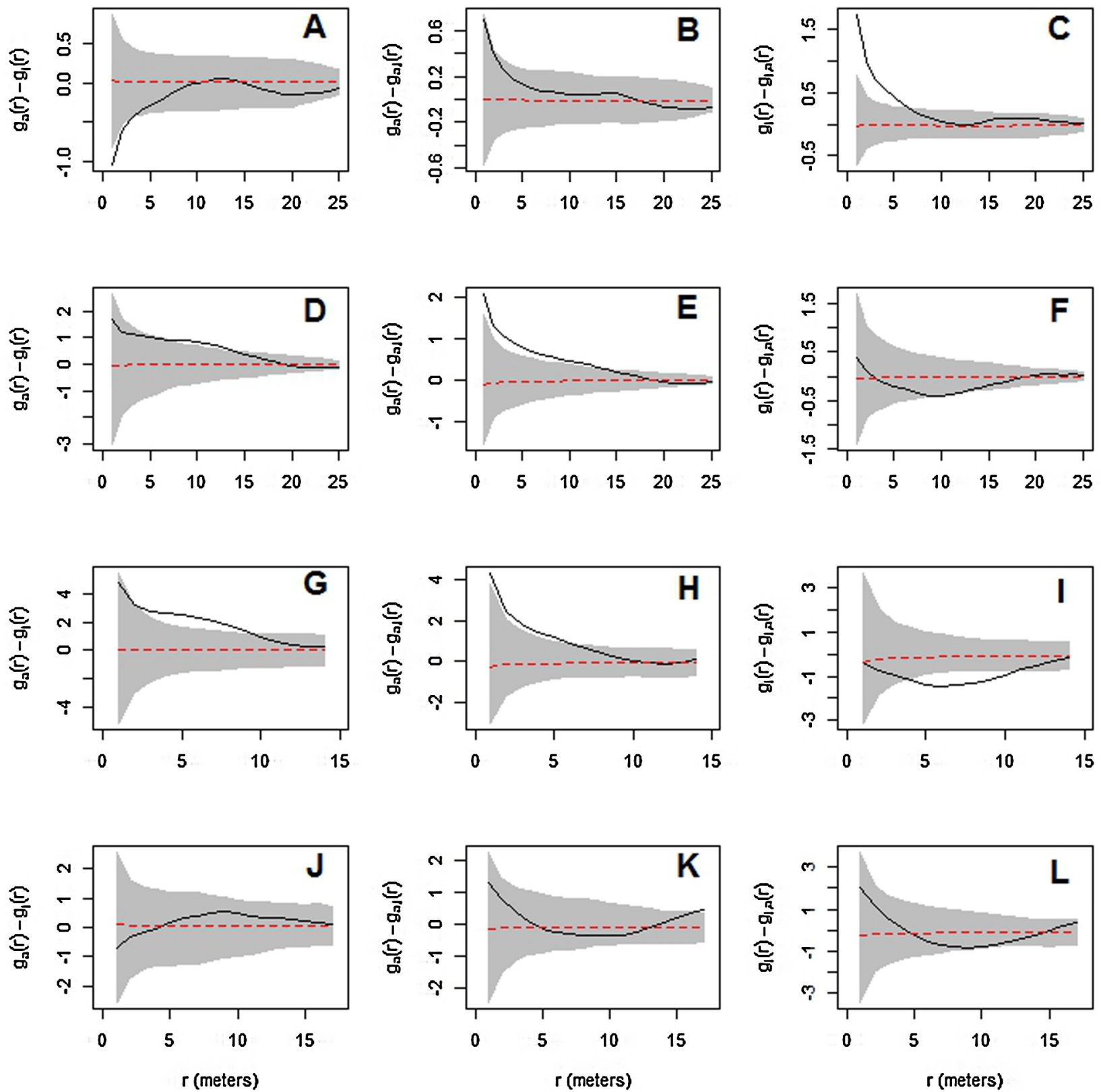

Fig. 5. Differences of $g$-functions using a null model of random labeling, where subscript $a$ indicates adult population and $j$ indicates juvenile population. (A-C), Cyathea caracasana in Chamusquín A plot. (D-F), Alsophila engelii in Chamusquín B plot. (G-I), Alsophila engelii in Chamusquín B plot. (J-L) Cyathea caracasana in San Francisco plot.

significantly heterogeneous. Although C. caracasana is considered a long-lived pioneer (Finegan, 1992) and does not recruit young sporophytes under closed canopies (Arens and Baracaldo, 1998), when overtopped by a competing canopy, it can enter a "persistence mode" characterized by low growth rates, longer lived leaves and ceased spore production (Arens, 2001). Under such circumstances, it shows a shade-tolerant behavior, waiting until a gap opens to resume growth (i.e., similar to a sapling bank). It seems plausible that most of the "adults" and "juveniles" in San Francisco are suppressed individuals in the "persistence mode". This would explain the absence of NDD signals and the random homogeneous spatial pattern in this stand. The low number of Cyathea individuals found in San Francisco concurs with this hypothesis and could indicate, as suggested by Arens (2001), that suppressed individuals are progressively dying in the shade environment. Since most gaps in the territory are small, between 20 and $150 \mathrm{~m}^{2}$ (Homeier and Breckle, 2008), population dynamics may be based on the persistence of these suppressed individuals during relatively long periods (Garwood, 1989). New sporophytes only recruit in relatively large gaps associated with landslides, which are relatively frequent in these steep valleys (Ohl and Bussmann, 2004).

The spatial structure of $A$. engelii populations did not concur with NDD expectations. Adults had a more clustered pattern than juveniles in both initial (Chamusquín B) and intermediate (Chamusquín A) succession stages. Several authors have pointed out some processes that can result in clumped adult distributions, such as low dispersal rates (Condit et al., 2000; Murrell, 2009), low recruitment rates (Murrell, 2009) and strong habitat filtering (Condit et al., 2000; Getzin et al., 2008). The spatial pattern of $A$. engelii could be explained by the existence of habitat filtering, as adults tend to appear in wetter soils (pers. obs.). Environmental dependence seems to be strong, as this pattern is maintained in two different succession stages. The signature of the differences of functions $g_{a}-g_{j}$ and $g_{j}-g_{j a}$ (also of the differences $K_{a}-K_{j}$ and $K_{j}-K_{j a}$ ) in 

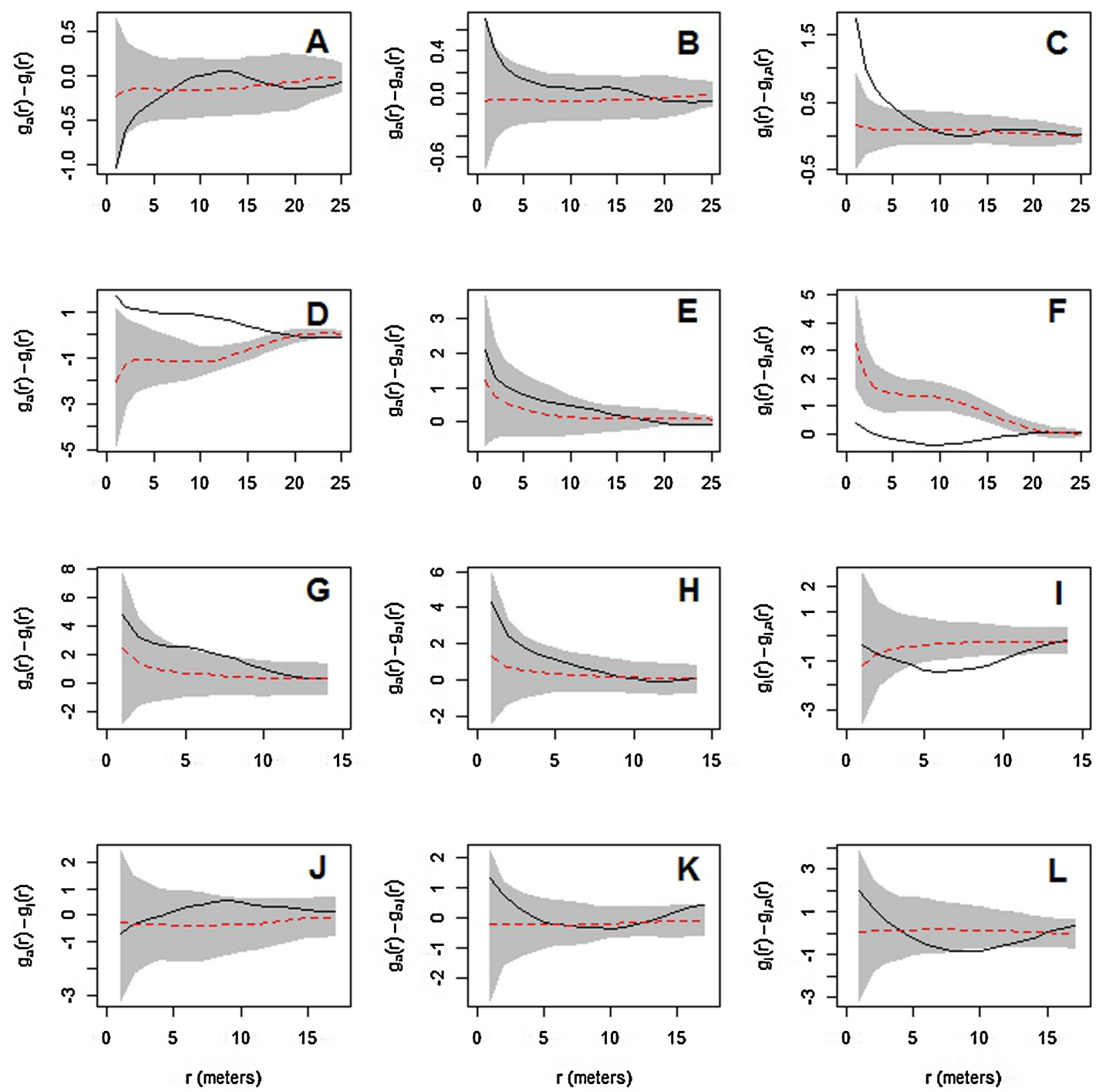

Fig. 6. Differences of $g$-functions using a "spatially varying" random labeling null model, where subscript $a$ indicates adult population and $j$ indicates juvenile population. $(A-C)$, Cyathea caracasana in Chamusquín A plot. (D-F), Alsophila engelii in Chamusquín B plot. (G-I), Alsophila engelii in Chamusquín B plot. (J-L), Cyathea caracasana in San Francisco plot.

the two plots is compatible with a heterogeneous distribution of larger and more aggregated clumps of adults and smaller clusters of juveniles (Getzin et al., 2008). Adult individuals may have been recruited in large gaps resulting from severe man-driven perturbations in these two forests. Once the forest canopy was recovered as a consequence of secondary dynamics, the recruitment of new tree ferns may be associated with small gaps that occur sporadically. The difference in aggregation between adults and juveniles is larger in Chamusquín A than in Chamusquín B, which is compatible with differences in habitat quality. If so, this would have a significant effect on the initial density of the new established population (i.e., adults) but would not affect the structure of new recruits. The spatially varying null model discarded the segregation of adults (in accordance with the significant positive effects of adults on the log-linear models of juvenile intensity) and confirmed that recruitment does not occur in independent gaps but is interspersed with clusters of adults, probably associated to the same wetter habitats but in smaller gaps than those where adults were recruited. All of these results reinforce our interpretation that some habitat filtering (Condit et al., 2000; Getzin et al., 2008) could be responsible for the spatial distribution of Alsophila adults.

\section{Conclusions}

Our study shows that tree ferns respond to environmental heterogeneity and some demographic processes (i.e., NDD) in the same way as spermatophytes and that their study can be tackled by using spatial point pattern techniques. This study described the similar signals for populations whose heterogeneity responded to different predictors, indicating the appropriateness of the case-control design used to examine NDD. Furthermore, the models using information from tree functional types explained the first order 
heterogeneity in most of the observed patterns. Our findings suggest that the effects of environmental heterogeneity must be factored out if we want to test the effects of NDD. If heterogeneity is not factored out, the detection of clustered patterns of adults could not be interpreted as a clear deviation from theoretical expectations under a process of density dependence thinning, i.e., a decline in aggregation with increasing size/age classes (Getzin et al., 2008). Moreover, as different ecological processes may lead to the same spatial pattern (Cale et al., 1989; Perry et al., 2006; McIntire and Fajardo, 2009), the factors influencing the inhomogeneous distribution of tree ferns should be detected using adequate functions. Our approach allows a better understanding of the patterns and the subsequent analysis of density dependence. As Murrell (2009) pointed out, the increase in aggregation through size classes is possible, as we have reported here for $A$. engelii. It is surprising how few studies have aimed to unveil the ecological determinants of tree fern performance and their demography. Further research is needed to gain insight into how plant diversity is assembled and coexists in tropical forests.

\section{Acknowledgements}

This study was partially supported by projects A/024796/09 and A/030244/10 from the Spanish Agency for International Development Cooperation (AECID) and projects CGL-2009-13190-C03-02 (ISLAS ESPACIO) and CGL-2012-38427 (MOUNTAINS) of the Spanish Ministry of Economy and Competitiveness and REMEDINAL2 (P2009/AMB-1783).Julia Chacón-Labella is supported by a FPI grant linked to project CGL-2009-13190 (ISLAS) awarded by the Spanish Ministry of Economy and Competitiveness. We thank Hans de Kroon, Kirk A. Moloney, George Perry and one anonymous reviewer for their valuables comments on this manuscript. We also thank Lori de Hond for her work improving the English of this manuscript.

\section{Appendix A. Supplementary data}

Supplementary material related to this article can be found, in the online version, at http://dx.doi.org/10.1016/j.ppees. 2014.02.003.

\section{References}

Arens, N.C., Baracaldo, P.S., 1998. Distribution of tree ferns (Cyatheaceae) across the successional mosaic in an Andean cloud forest, Nariño, Colombia. Am. Fern J. 88 $60-71$.

Arens, N.C., Baracaldo, P.S., 2000. Variation in tree fern stipe length with canopy height: tracking preferred habitat through morphological change. Am. Fern J. $90,1-15$.

Arens, N.C., 2001. Variation in performance of the tree fern Cyathea caracasana (Cyatheaceae) across a successional Mosaic in an Andean cloud forest. Am. J. Bot. 88, 545-551.

Baddeley, A., Turner, R., 2000. Practical maximum pseudolikelihood for spatial point patterns. Aust. N. Zeal. J. Stat. 42, 283-322.

Baddeley, A., Turner, R., 2005. Spatstat: an R package for analyzing spatial point patterns. J. Stat. Softw. 12, 1-42.

Baddeley, A.J., Møller, J., Waagepetersen, R., 2000. Non- and semi-parametric estimation of interaction in inhomogeneous point patterns. Stat. Neerl. 54, 329-350.

Bagchi, R., Henrys, P.A., Brown, P.E., Burslem, D.F.R.P., Diggle, P.J., Gunatilleke, C.V.S. Gunatilleke, I.A.U.N., Kassim, A.R., Law, R., Noor, S., Valencia, R.L., 2011. Spatia patterns reveal negative density dependence and habitat associations in tropical trees. Ecology 92, 1723-1729.

Beck, E., Makeschin, F., Haubrich, F., Richter, M., Bendix, J., 2007. The ecosystem (Reserva Biológica San Francisco). In: Beck, E., Bendix, J., Kottke, I., Makeschin, F., Mosandl, R. (Eds.), Gradients in a Tropical Mountain Ecosystem of Ecuador. Springer, Berlin, Heidelberg/New York, pp. 1-14

Bellingham, P.J., Wiser, S.K., Hall, G.M.J., Alley, J.C., Allen, R.B., Suisted, P.A., 1999. Impacts of possum browsing on the long-term maintenance of forest biodiversity. Sci. Conserv. 103, 1-59.

Besag, J., 1977. Contribution to the discussion of Dr Ripley's paper. J. R. Stat. Soc. Ser. B 39, 193-195.

Bittner, J., Breckle, S.W., 1995. The growth rate and age of tree fern trunks in relation to habitats. Am. Fern J. 85, 37-42.
Burnham, K.P. Anderson, D.R, 2002. Model Selection and Multi-Model Inference: A Practical Information - Theoretic Approach. Springer, New York.

Bystriakova, N., Bader, M., Coomes, D.A., 2011. Long-term tree fern dynamics linked to disturbance and shade tolerance. J. Veg. Sci. 22, 72-84.

Cale, W.G., Henebry, G.M., Yeakley, J.A., 1989. Inferring process from pattern in natural communities. Bioscience 39,600-605.

Condit, R., Ashton, P.S., Baker, P., Bunyavejchewin, S., Gunatilleke, S., Gunatilleke, N. Hubbell, S.P., Foster, R.B., Itoh, A., LaFrankie, J.V., Lee, H.S., Losos, E., Manokaran, N., Sukumar, R., Yamakura, T., 2000. Spatial patterns in the distribution of tropical tree species. Science 288, 1414-1418.

Connell, J.H., 1971. On the role of natural enemies in preventing competitive exclusion in some marine animals and in rain forest trees. In: Den Boer, P.J., Gradwell, G. (Eds.), Dynamics of Populations. Pudoc, Wageningen, pp. 298-312.

Chapin, F.S., McGraw, J.B., Shaver, G.R., 1989. Competition causes regular spacing of alder in Alaskan shrub tundra. Oecologia 79, 412-416.

De la Cruz, M., Romao, R.L., Escudero, A., Maestre, F.T., 2008. Where do seedlings go? A spatio-temporal analysis of seedling mortality in a semi-arid gypsophyte. Ecography 31, 720-730.

Diggle, P.J., Chetwynd, A.G., 1991. Second-order analysis of spatial clustering for inhomogeneous populations. Biometrics 47, 1155-1163.

Diggle, P.J., 2003. Statistical Analysis of Point Patterns, second ed. Arnold, London, UK.

Diggle, P.J., Gómez-Rubio, V., Brown, P.E., Chetwynd, A.G., Gooding, S., 2007. Secondorder analysis of inhomogeneous spatial point processes using case-control data. Biometrics 63, 550-557.

Dixon, R.K., 2002. Ripley's K function. In: El-Shaarawi, A.H., Piergorsch, W.W. (Eds.) The Encyclopedia of Environmetrics. John Wiley \& Sons Ltd., New York, United States.

Finegan, B., 1992. Bases ecológicas para la silvicultura. Tema 1. V curso internacional sobre silvicultura y manejo de bosques tropicales.

Franklin, J., Rey, S., 2007. Spatial patterns of tropical forest trees in western Polynesia suggest recruitment limitations during secondary succession. J. Trop. Ecol. 23 , $1-11$

Garwood, N., 1989. Tropical soil seed banks. In: Leck, MAP.V., Simpson, RL (Eds.), Ecology of Soil Seed Banks. Academic Press, San Diego, CA, pp. 149-209.

Getzin, S., Wiegand, T., Wiegand, K., He, F., 2008. Heterogeneity influences spatia patterns and demographics in forest stands. J. Ecol. 96, 807-820.

He, F., Duncan, R.P., 2000. Density-dependent effects on tree survival in an oldgrowth douglas fir forest. J. Ecol. 88, 676-688.

Homeier, J., Breckle, S.W., 2008. Gap-dynamics in a tropical montane forest in South Ecuador. In: Beck, E., Bendix, J., Kottke, I., Makeschin, F., Mosandl, R. (Eds.), Gradients in a Tropical Mountain Ecosystem of Ecuador. Ecological Studies, vol. 198. Springer Verlag, Berlin, Heidelberg, pp. 311-317 (Chapter 23).

Hubbell, S.P., Ahumada, J.A.R., Condit, R., Foster, R.B., 2001. Local neighborhood effects on long-term survival of individual trees in a Neotropical forest. Ecol. Res. 16, 859-875.

Illian, J., Penttinen, A., Stoyan, H., Stoyan, D., 2008. Statistical Analysis and Modelling of Spatial Point Patterns. John Wiley \& Sons, Chichester.

Janzen, D.H., 1970. Herbivores and the number of tree species in tropical forests. Am. Nat. 104, 501-528.

Jones, M.M., Tuomisto, H., Clark, D.B., Olivas, P., 2006. Effects of mesoscale environmental heterogeneity and dispersal limitation on floristic variation in rain forest ferns. J. Ecol. 94, 181-195.

Jones, M.M., Olivas Rojas, P., Tuomisto, H., Clark, D.B., 2007. Environmental and neighbourhood effects on tree fern distributions in a neotropical lowland rain forest. J. Veg. Sci. 18, 13-24.

Kenkel, N.C., 1988. Pattern of self-thinning in jack pine: testing the random mortality hypothesis. Ecology 69, 1017-1024.

Kramer, K.U., 1993. Distribution patterns in major pteridophyte taxa relative to those of angiosperms. J. Biogeogr. 20, 287-291.

Law, R., Illian, J., Burslem, D.F.R.P., Gratzer, G., Gunatilleke, C.V.S., Gunatilleke, I.A.U.N., 2009. Ecological information from spatial patterns of plants: insights from point process theory. J. Ecol. 97, 616-628.

Lehnert, M., (Ph.D. thesis) 2007. Diversity and evolution of pteridophytes, with emphasis on the Neotropics. Georg-August-Universität zu Göttingen.

Loosmore, N.B., Ford, E.D., 2006. Statistical inference using the G or K point pattern spatial statistics. Ecology 87, 1925-1931.

Márquez, A.L., Real, R., Vargas, J.M., Salvo, A.E., 1997. On identifying common distribution patterns and their causal factors: a probabilistic method applied to pteridophytes in the Iberian Peninsula. J. Biogeogr. 24, 613-631.

McIntire, E.J.B., Fajardo, A., 2009. Beyond description: the active and effective way to infer processes from spatial patterns. Ecology 90, 46-56.

Mehltreter, K., García-Franco, J.G., 2008. Leaf phenology and trunk growth of the deciduous tree fern Alsophila firma (Baker) D.S. Conant in a lower montane Mexican Forest. Am. Fern J. 98, 1-13.

Moeur, M., 1997. Spatial models of competition and gap dynamics in old-growth Tsuga heterophylla/Thuja plicata forests. For. Ecol. Manage. 94, 175-186.

Murrell, D.J., 2009. On the emergent spatial structure of size-structured populations: when does self-thinning lead to a reduction in clustering? J. Ecol. 97 256-266.

Ohl, C., Bussmann, R., 2004. Recolonisation of natural landslides in tropical mountain forests of Southern Ecuador. Feddes Repertorium 115, 248-264.

Perry, G.L.W., Miller, B.P., Enright, N.J., 2006. A comparison of methods for the statistical analysis of spatial point patterns in plant ecology. Plant Ecol. 187, $59-82$ 
Perry, G.L.W., Enright, N.J., Miller, B.P., Lamont, B.B., 2013. Do plant functional traits determine spatial pattern? A test on species-rich shrublands, Western Australia. J. Veg. Sci. 24, 441-452.

Plotkin, J.B., Chave, J., Ashton, P.S., 2002. Cluster analysis of spatial patterns in Malaysian tree species. Am. Nat. 160, 629-644.

Poorter, L., Bongers, L., Bongers, F., 2006. Architecture of 54 moist-forest tree species: traits, trade-offs, and functional groups. Ecology 87, 1289-1301.

Purves, D.W., Law, R., 2002. Experimental derivation of functions relating growth of Arabidopsis thaliana to neighbour size and distance. J. Ecol. 90, $882-894$.

R Development Core Team, 2011. R: A language and environment for statistical computing. R Foundation for Statistical Computing, Vienna, Austria. ISBN 3900051-07-0, URL http://www.R-project.org/

Ripley, B.D., 1976. The second-order analysis of stationary point processes. J. Appl. Probab. 13, 255-266.

Ripley, B.D., 1978. Spectral analysis and the analysis of pattern in plant communities. J. Ecol. 66, 965-981.

Roberts, N.R., Dalton, P.J., Jordan, G.J., 2005. Epiphytic ferns and bryophytes of Tasmanian tree-ferns: a comparison of diversity and composition between two host species. Austral Ecol. 30, 146-154

Rollenbeck, R., 2006. Variability of precipitation in the Reserva Biólogica San Francisco, Southern Ecuador. Lyonia 9, 43-51.

Seiler, R.L., 1981. Leaf turnover rates and natural history of the central American tree fern Alsophila salvinii. Amer. Fern J. 71, 75-81.

Seiler, R.L., 1995. Verification of estimated growth rates in the tree fern Alsophila salvinii. Amer. Fern J. 85, 96-97.

Smale, M.C., Burns, B.R., Smale, P.N., Whaley, P.T., 1997. Dynamics of upland podocarp/broadleaved forest on Mamaku Plateau, central North Island, New Zealand. J. R. Soc. N. Z. 27, 513-532.
Sterner, R.W., Ribic, C.A., Schatz, G.E., 1986. Testing for life historical changes in spatial patterns of four tropical tree species. J. Ecol. 74, 621-633.

Stoll, P., Bergius, E., 2005. Pattern and process: competition causes regular spacing of individuals within plant populations. J. Ecol. 93, 395-403.

Stoyan, D., Stoyan, H., 1994. Fractals, random shapes and point fields: methods of geometrical statistics. Wiley, United Kingdom.

Terborgh, J., 2012. Enemies maintain hyperdiverse tropical forests. Am. Nat. 179, 303-314.

Turner, I.M., 2004. The Ecology of Trees in the Tropical Rain Forest. Cambridge University Press, Cambridge.

Uriarte, M., Condit, R., Canham, C.D., Hubbell, S.P., 2004. A spatially explicit model of sapling growth in a tropical forest: does the identity of neighbours matter? J. Ecol. 92, 348-360.

Watkins Jr., J.E., Mack, M.K., Mulkey, S.S., 2007. Gametophyte ecology and demography of epiphytic and terrestrial tropical ferns. Am. J. Bot. 94, 701-708.

Whitmore, T.C., 1989. Canopy gaps and the two major groups of forest trees. Ecology $70,536-538$

Wiegand, T., Moloney, K.A., 2004. Rings, circles, and null-models for point pattern analysis in ecology. Oikos 104, 209-229.

Wiegand, T., Gunatilleke, S., Gunatilleke, N., 2007. Species associations in a heterogeneous Sri Lankan Dipterocarp forest. Am. Nat. 170, 77-95.

Wright, J., 2002. Plant diversity in tropical forests: a review of mechanisms of species coexistence. Oecologia 130, 1-14.

Zhu, Y., Mi, X., Ren, H., Ma, K., 2010. Density dependence is prevalent in a heterogeneous subtropical forest. Oikos 119, 109-119.

Zimmerman, J.K., Thompson, J., Brokaw, N., 2008. Large tropical forest dynamics plots: testing explanations for the maintenance of species diversity. In: Carson, W., Schnitzer, S. (Eds.), Tropical Forest Community Ecology. Blackwell Publications, Blackwell, Oxford, pp. 98-117. 